\title{
Delleman syndrome: a case report and review
}

\author{
R De Cock, A Merizian
}

\begin{abstract}
A case of oculocerebrocutaneous syndrome is presented, to our knowledge the first to be reported in West Bank and Gaza. The child was of consanguinous parents. The clinical features of orbital cyst, periorbital cutaneous malformations, and cerebral malformations are described, together with a brief review of previous reports. The need for neurological follow-up of these cases is emphasised.
\end{abstract}

The oculocerebrocutaneous syndrome was described by Delleman and Oorthuys in $1981^{1}$ who reported on two patients with congenital orbital cysts, cerebral malformations, and focal skin defects. Further cases have since been described. ${ }^{2-4}$ We present an infant with this syndrome of consanguinous parents, a feature not previously reported. The oculocerebrocutaneous syndrome is not widely recognised among ophthalmologists and may well be less rare than hitherto thought.

St John Ophthalmic Hospital, Jerusalem R De Cock

Makassed Islamic Charitable Hospital, Jerusalem

A Merizian

Correspondence to: Romain De Cock, FRCS, FCOphth, St John Ophthalmic Hospital, PO Box 19960, Jerusalem, Israel. Accepted for publication 11 July 1991

Figure 2 CT scan showing left cerebellar atrophy $(A)$ and cystic defects $(B)$.

\section{Case report}

This female infant is the third child of healthy consaguinous (first cousin) Palestinian parents aged 27 (mother) and 31 (father) with two other normal children. Pregnancy and home delivery were uncomplicated. A the age of $2 \mathrm{~h}$, the infant presented to St John Ophthalmic Hospital with a left orbital mass.

A large translucent cyst protruded from the left orbit with no visible ocular tissue (Fig 1). A coloboma was present at the junction of the medial and central thirds of the left upper lid.

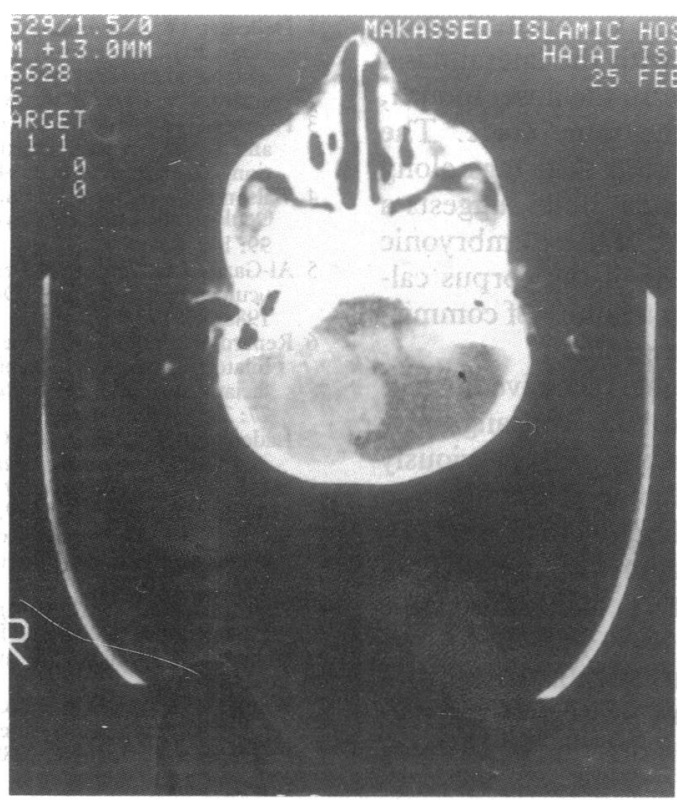

Fig $2 A$

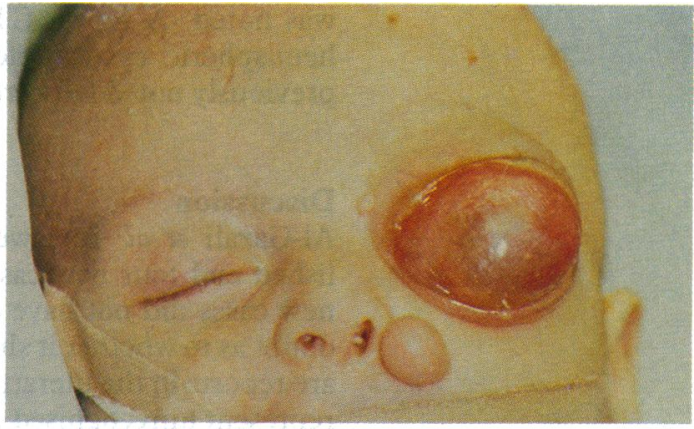

Figure 1 Left orbital cyst and periorbital skin tag.

The right eye was normal. A large skin tag was present below the left orbit; smaller appendages involved the left side of the nasal septum and left lower lid margin. Pigmented areas of very thin dermis and small pitted skin lesions were present above the left ear and on the forehead.

The infant weighed $2800 \mathrm{~g}$, measured $47 \mathrm{~cm}$ with a head circumference of $31 \mathrm{~cm}$ (below the 3rd percentile). Examination of the respiratory, cardiovascular, genitourinary, and neurological systems was normal. Karyotype was XX, 46.

Computed tomographic (CT) scan showed a cystic left orbital mass with no intracranial communication and left cerebellar atrophy. At surgery clear fluid was aspirated from the cyst which was freed from the surrounding conjunctiva and periorbita and excised together with solid tissue lying deep to the cyst. Following conjunctival closure a conformer was inserted and maintained in the orbit with a central tarsorrhaphy.

Histology showed a severely disorganised microphthalmic globe with orbital cyst. The

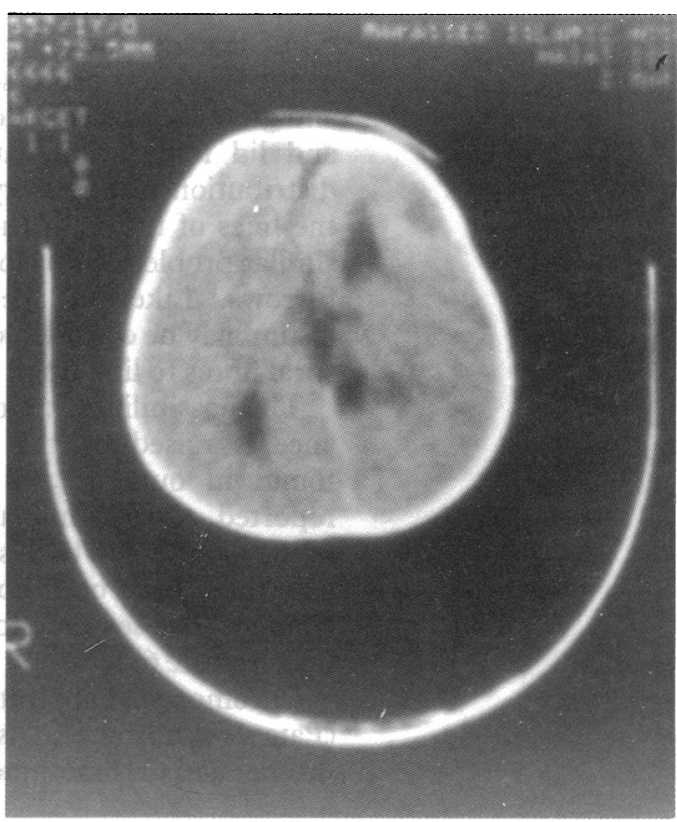

Fig $2 B$ 
incompletely formed eye was represented by dysplastic retinal tissue with rosette formation, ciliary muscle, pigment epithelium, and some scleral condensation of fibrous connective tissue. Calcified lens material and islands of cartilaginous metaplasia were also present. The cyst wall consisted of neuroepithelium and glial tissue.

At 16 months moderate developmental delay was noted. A repeat CT scan showed multiple hemispheric cystic defects in addition to the previously noted left cerebellar atrophy (Fig 2).

\section{Discussion}

Al-Gazali et $a l^{5}$ reviewed five previously published and four new cases. However one of the new cases did not have cerebral lesions, casting doubt as to whether it should be included. There are reports in the literature which most probably represent unrecognised cases of the syndrome. ${ }^{67}$

The most obvious feature is the presence of an orbital cyst which may be bilateral (three cases) and can be associated with microphthalmos (four cases) and/or eyelid coloboma (four cases). The cerebral malformations noted were multiple cystic spaces in the brain which in four cases were accompanied by agenesis of the corpus callosum. Psychomotor retardation and convulsions were present in seven cases. Cutaneous manifestations include the presence of accessory facial skin tags in the periorbital area and foci of dermal hypoplasia seen as pink or pigmented areas where subcutaneous fat prolapses through atrophic dermis.

Our case shows the features of the syndrome described by Delleman and Oorthuys. Detailed histological examination of the cyst was performed in only one previously reported case. ${ }^{+}$ The pathological findings in our case confirm the hamartomatous nature of the cyst with primitive neuroectodermal, retinal, and glial tissue.

Lesions involving orbital, cerebral, and facial structures point to a disruption of embryonic development at a very early stage. Microphthalmos with cyst is related to incomplete closure of the embryonic fissure, normally occurring at 5-6 weeks, ${ }^{8}$ with cystic extension of neuroretinal tissue through the defect into the orbit. ${ }^{9}$ Fusion of the maxillary processes with the lateral nasal and globular processes to form the nose, mouth, and lid folds occurs at the same stage. The distribution of accessory facial skin tags along the lines of fusion of the facial buds suggests a similar problem with closure of these embryonic furrows. ${ }^{6}$ Likewise, agenesis of the corpus callosum may be considered as a failure of commissural fibres to link up in the midline.

The possibility of autosomal recessive inheritance is raised by the parental consanguinity found in our case, a feature not previously reported. Ophthalmic and general examination of the parents and both siblings were normal. To date there have been no reports of any affected siblings. The sex ratio for this condition so far is male:female 6:4.

Chromosomal aberrations such as trisomy 13 (Patau's syndrome), trisomy 18 (Edward's syndrome) and chromosome 18 deletion defect may give rise to microphthalmos together with facial and neurological abnormalities. ${ }^{10}$ Accessory skin tags are a feature of Goldenhar's syndrome in which upper eyelid colobomas and microphthalmos may also occur. However in Goldenhar's syndrome epibulbar dermoids are the more typical ocular feature, the skin tags are found in the preauricular rather than the periorbital region and cerebral cystic defects are not part of the clinical picture. Microphthalmos, coloboma and focal dermal hypoplasia may occur in Goltz syndrome ${ }^{11}$ but other characteristic abnormalities include polysyndactyly and poor dentition. Goltz syndrome is inherited as an X-linked dominant condition occurring only in females as it is lethal in males. Ultrasound and CT may be helpful in excluding meningoencephalocele or tumour. ${ }^{12}$

True anophthalmia is extremely rare; more commonly some attempt at eye formation gives rise to a congenital cystic eye or microphthalmos with or without cyst. The cyst may be sufficiently large to obscure the microphthalmic eye. Depending on size the orbital cyst may be either left alone, aspirated, or excised. Aspiration may need to be repeated as reaccumulation of fluid is not uncommon and may occur rapidly. ${ }^{7}$ Excision of the cyst is facilitated by initial aspiration following which it is readily dissected free of the conjunctiva and periorbita. As much conjunctiva as possible must be preserved and frequent introduction of increasingly larger conformers is required to avoid socket contracture.

The need for neurological follow up is borne out by the psychomotor deficit documented in our patient. Progression of clinical and/or CT findings was noted in at least three of the previously reported cases ${ }^{135}$ one of whom died with hydrocephalus. Ophthalmologists should be aware of the possibility of cerebral malformations in patients with congenital orbital cysts and skin appendages.

We thank Dr Raja Rabah, Makassed Hospital and Professor Alec Garner, Institute of Ophthalmology, London for the pathology reports and Mrs Anne Zawahreh for administrative assistance.

1 Delleman JW, Oorthuys JWE. Orbital cyst in addition to congenital cerebral and focal dermal malformations: a new entity? Clin Genet 1981; 19: 191-8.

2 Delleman JW, Oorthuys JWE, Bleeker-Wagemakers EM, Ter Haar BGA, Ferguson JW. Orbital cyst in addition to congenital cerebral and focal dermal malformations: a new entity. Clin Genet 1984; 25: 470-2.

3 Ferguson JW, Hutchison HT, Rouse BM. Ocular, cerebral and cutaneous malformations: confirmation of an association. Clin Genet 1984; 25: 464-9.

4 Wilson RD, Traverse L, Hall JG, Flodmark CO, Rootman J. Oculocerebrocutaneous syndrome. Am F Ophthalmol 1985; 99: 142-8.

5 Al-Gazali LI, Donnai D, Berry SA, Say B, Mueller RF. The oculocerebrocutaneous (Delleman) syndrome. $\mathcal{F}$ Med Genet 1988; 25: 773-8.

6 Renard M, Fontaine M, Dhermy P, Caquet N. Microphtalmie bilatérale avec kystes orbitaires associée å des appendices faciaux surnuméraires. Bull Mem Soc Fr Ophtalmol 1964; 77: 297-316

7 Ladenheim J, Metrick S. Congenital microphthalmos with cyst formation. Am F Ophthalmol 1956; 41: 1059-62.

8 Mann I. The development of the human eye. London: British Medical Association, 1949.

9 Waring GO, Roth AM, Rodrigues MM. Clinicopathologic correlation of microphthalmos with cyst. Am $\mathcal{F}$ Ophthalmol 1976; 82: 714-21.

10 Yanoff M, Fine BS. Ocular pathology a text and atlas, 2nd ed. Philadelphia: Harper and Row, 1982.

11 Willetts GS. Focal dermal hypoplasia. Br f Ophthalmol 1974; 58: $620-4$.

12 Weiss A, Martinez C. Microphthalmos with cyst: clinical presentations and computer tomographic findings. $\mathcal{F}$ Pediatr Ophthalmol Strabismus 1985; 22: 6-12. 